Original Article

\title{
PHARMACOLOGICAL EVALUATION OF ZAFIRLUKAST IN EXPERIMENTALLY INDUCED GLOBAL CEREBRAL ISCHEMIA/REPERFUSION INJURY IN MICE
}

\author{
BIPIN KUMAR NAYAK*, ARUN KUMAR, PREETI KOTHIYAL
}

Division of Pharmaceutical Sciences, Shri Guru Ram Rai Institute of Technology and Science, Patel Nagar, Dehradun, Uttarakhand, India Email: bipinpharm2005@gmail.com

Received: 04 Apr 2017 Revised and Accepted: 21 Dec 2017

\begin{abstract}
Objective: Cysteinyl leukotrienes (CysLTs) are potent mediators of inflammation that are associated with cerebral ischemia/reperfusion (I/R) injury. The CysLTs receptor antagonist may offer protection against ischemic injury. The present study was designed to investigate the role of zafirlukast in experimentally induced global cerebral ischemia/reperfusion (I/R) injury in mice.

Methods: Global cerebral ischemia-reperfusion was induced by bilateral carotid artery occlusion for 17 min followed by 24 h reperfusion. Mice were randomly assigned to eight groups ( $\mathrm{n}=6$ per group): control, sham-operated, I/R control, prednisolone treated group (5 mg/kg, p. o.) for $10 \mathrm{~d}$, zafirlukast treated group (5, 10, $20 \mathrm{mg} / \mathrm{kg}, \mathrm{p}$. o.) for $10 \mathrm{~d}$ and combination group treated with zafirlukast (5 mg/kg, p. o.) + nifedipine (5 mg/kg, i. p.) for $10 \mathrm{~d}$ before ischemia/reperfusion. At the end of reperfusion ( $24 \mathrm{~h})$, a blood sample was collected from retro-orbital route and mice's brain was removed by cervical dislocation to measure serum lactate dehydrogenase (LDH), serum nitrite concentration, malondialdehyde (MDA), and cerebral infarct size.
\end{abstract}

Results: Zafirlukast showed the dose-dependent neuroprotective activity by a significant decrease in lipid peroxidation, lactate dehydrogenase, serum nitrite level and cerebral infarct size. The high dose of zafirlukast (20 mg/kg, p. o.) and combination of zafirlukast (5 mg/kg, p. o.) with nifedipine $(5 \mathrm{mg} / \mathrm{kg}$, i. p.) showed the most potent neuroprotective effect against ischemic/reperfusion (I/R) group.

Conclusion: This original study demonstrated the potency of zafirlukast in global cerebral ischemia/reperfusion injury. Also zafirlukast, in combination with nifedipine could represent a therapeutic approach to reduce inflammation associated with ischemia injury.

Keywords: Zafirlukast, Ischemia/reperfusion, Oxidative stress, Inflammation

(C) 2018 The Authors. Published by Innovare Academic Sciences Pvt Ltd. This is an open access article under the CC BY license (http://creativecommons.org/licenses/by/4.0/) DOI: http://dx.doi.org/10.22159/ijpps.2018v10i2.21633

\section{INTRODUCTION}

Stroke is one of the leading causes of death and adult long-term disability worldwide, with ischemic stroke comprising more than $85 \%$ of total cases, as a consequence of a permanent or transient occlusion by either embolism or thrombosis of cerebral arteries [13]. In global cerebral ischemia, reduction of glucose and oxygen in whole brain, depending on the cerebral artery occluded. Ischemia produces serious damage of brain tissue followed by molecular and biochemical alteration [4-6]. One of the main causes of global cerebral ischemia is cardiac arrest, which leads to neurological consequence to the patients [7]. The potential treatment of ischemic stroke is still lacking due to narrow therapeutic window [3]. The exact mechanism involved in ischemic stroke through pathophysiological processes such as oxidative stress, activation of voltage-gated calcium channel, inflammation, excitotoxicity, apoptosis and necrosis, and mitochondrial dysfunction [8-12]. To date, thrombolytic agent recombinant tissue plasminogen activator (rt-PA) mainly recommended for the treatment of ischemic stroke, the normal prognosis is unsatisfactory [13]. Therefore, it is necessary to develop new therapeutic agent for the treatment of ischemic stroke.

Zafirlukast is cysteinyl leukotrienes (CysLTs) antagonist that has an anti-inflammatory and antiasthma effect [14]. Leukotrienes are a group of eicosanoid inflammatory mediators produced in leukocyte by the oxidation of arachidonic acid by the enzyme 5-lipoxygenase $[15,16]$. The Leukotrienes were first discovered in leukocyte, but have since found in other immune cells.

Pharmacological studies indicated that cysteinyl Leukotrienes activate at least two receptors, cysteinyl Leukotrienes receptor 1 (CysLTR1) and Cysteinyl Leukotrienes receptor 2 (CysLTR2) and this two cysteinyl-leukotrienes receptor are present on endothelial cells mast cells, and eosinophil. They stimulate proinflammatory activities when activation such as endothelial cell adherence and chemokine production by mast cells [17]. The level of Cysteinyl Leukotrienes (CysLTs), has been increased in asthmatic patient and also excess Cysteinyl Leukotrienes (CysLTs) can induce anaphylactic shock [18]. After a period of global cerebral ischemia results in activation, accumulation and adherence of circulating leukocytes to the endothelium of blood vessels $[19,20]$. There is a univocal relationship between the accumulation of high amount of Cysteinyl Leukotrienes (CysLTs) and enhanced leukocyte aggregation which in turn will activate toxic oxygen radicals and hydrolytic enzyme that contribute to the full expression of ischemia-reperfusion injury [21, 22].

Research findings by Corser-Jensen et al. [23] point towards the increased production of Cysteinyl Leukotrienes (CysLTs) in the ischemic brains, and this increase interacted with blood-brain barrier (BBB) dysfunction and brain damage. Therefore, aggregation of Cysteinyl Leukotrienes (CysLTs) in the brain may play a key role in cerebral ischemia.

The previous studied on 5-lipoxygenase inhibitors have been reported to offer a protective effect on cerebral ischemia [24]. In addition, montelukast is a selective Cysteinyl Leukotrienes (CysLTs) receptor antagonist, protected mice and rat against global and focal cerebral ischemia [25]. In the present study, zafirlukast, the prototype Cysteinyl Leukotrienes (CysLTs) receptor antagonist has the same neuroprotective effect as montelukast. Additionally, this experimental investigational was conducted to unveil the exact mechanism of its neuroprotective effect which needs further clarification.

\section{MATERIALS AND METHODS}

\section{Animals}

Swiss albino mice of either sex weighing 20-25 g were procured from animal house facility of Shri Guru Ram Rai Institute of Technology and Science, Patel Nagar, Dehradun. During the experiment, mice were acclimatized in the departmental animal house facility and housed in polypropylene cage with husk bedding 
(renewed every $48 \mathrm{~h}$ ), under $12: 12 \mathrm{~h}$ light dark cycle at $25^{\circ} \mathrm{C} \pm 5{ }^{\circ} \mathrm{C}$. The mice were allowed free access to commercial pellet diet and water ad libitum. The protocol was approved by the Institutional Animal Ethics Committee (Registration No. 264/PO/ReBi/S/ 2002 /CPCSEA) and experiment was carried out in accordance with the CPCSEA guidelines.

\section{Experimental protocol}

Animals were randomly allocated into eight groups $(n=6$ mice per group).

* Group 1:-Normal control group.

* Group 2:-Sham Control: Only surgical procedure was performed on $10^{\text {th }} \mathrm{d}$.

* Group 3:-Negative control group: Vehicle will be administered for $10 \mathrm{~d}$, then BCA was occluded for $17 \mathrm{~min}$, followed by reperfusion for $24 \mathrm{~h}$.

* Group 4:-Standard group treated with Prednisolone $(5 \mathrm{mg} / \mathrm{kg}$, p. o.) for $10 \mathrm{~d}$ before occlusion

* Group 5:-Test group treated with Zafirlukast (5 mg/Kg, p. o.) for $10 \mathrm{~d}$ before occlusion.

* Group 6:-Test group treated with Zafirlukast (10 mg/kg, p. o.) for $10 \mathrm{~d}$ before occlusion.

* Group 7:-Test group treated with Zafirlukast (20 mg/kg, p. o.) for $10 \mathrm{~d}$ before occlusion.

* Group 8:-Test group treated with Zafirlukast $(5 \mathrm{mg} / \mathrm{kg}, \mathrm{p}$. o.)+Nifedipine ( $5 \mathrm{mg} / \mathrm{kg}$, i. p) for $10 \mathrm{~d}$ before occlusion.

\section{Induction of global cerebral ischemia}

The experimental mice were anesthetized with chloral hydrate (400 $\mathrm{mg} / \mathrm{kg}$, i. p.). A midline ventral incision was made in the neck to expose the right and left common carotid arteries, which were isolated from surrounding tissue and vagus nerve. A cotton thread was passed below both the carotid arteries. Global cerebral ischemia was induced by occluding the bilateral carotid arteries. Then after 17 min of global cerebral ischemia, reperfusion was allowed for $24 \mathrm{~h}$. The incision was sutured back in layers. The sutured area was cleaned with $70 \%$ ethanol and was sprayed with antibiotic (Neosporin) dusting powder. Animals were transferred to individually their home cage and were allowed to recover overnight. Body temperature of mice was maintained at $37^{\circ} \mathrm{C}$ by heated surgical platform [26, 27].

\section{Assessment of cerebral infarct size}

At the end of $24 \mathrm{~h}$ of reperfusion after global cerebral ischemia, animals were sacrificed by cervical dislocation under light anesthesia then brain was removed. The brain was kept overnight at $4{ }^{\circ} \mathrm{C}$ in the freezer. Frozen brain was sliced into uniform sections of about $1 \mathrm{~mm}$ thickness. The slices were incubated with $1 \%$ Triphenyltetrazolium chloride (TTC) at $37^{\circ} \mathrm{C}$ in $0.2 \mathrm{M}$ tris buffer (pH 7.4) for 20 min. Triphenyltetrazolium chloride (TTC) is converted to a red formazone pigment by nicotinamide adenine dinucleotide (NAD) and lactate dehydrogenase and thus stained the viable cell deep red. The infarcted cells lost the enzymes as well as a cofactor and thus remain unstained dull yellow. The brain slices were placed over a glass plate. A transparent plastic grid with 100 squares in $1 \mathrm{~cm}^{2}$ was placed over it. The average area of each brain slice was calculated by counting the number of squares on either side. Correspondingly, the number of squares falling over the non-stained dull yellow area was also counted. Infarcts area was expressed as a percentage of the total brain volume. Whole brain slices were weighed. Infarcted area was expressed as a percentage of the total brain volume. Whole brain slices were weighed. Infarcted dull yellow part was dissected out and weighed. Infarct size was expressed as a percentage of the total wet weight of the brain [27].

\section{Preparation of post-mitochondrial supernatant (PMS)}

The animals were sacrificed with cervical dislocation under light anesthesia. The whole brain was carefully removed from the skull and washed in cooled $0.9 \%$ saline, then kept on an ice bath and subsequently blotted on filter paper. The fresh whole brain was weighed and homogenized in cold phosphate buffer $(0.1 \mathrm{M}, \mathrm{pH} 7.4)$ using a homogenizer. Then homogenate was centrifuged at 10,000 rpm for $15 \mathrm{~min}$ at $4^{\circ} \mathrm{C}$ and the post-mitochondrial supernatant was kept on ice until assayed [28].

\section{Estimation of protein}

The content of total protein in tissue homogenate was measured following the method of Lowry et al. using bovine serum albumin as a standard [29].

\section{Estimation of lipid peroxidation}

The extent of lipid peroxidation level was determined as the concentration of thiobarbituric acid reactive substances (TBARS), according to the method of Ohkawa et al. [30]. $0.2 \mathrm{ml}$ of tissue homogenate, $1.5 \mathrm{ml}$ acetic acid (20\%, pH 3.5), $1.5 \mathrm{ml}$ thiobarbituric acid $(0.8 \%)$ and $0.2 \mathrm{ml}$ of sodium dodecyl sulfate were added and gently vortexed. The mixture was kept for $1 \mathrm{hr}$ in a boiling water bath at $95{ }^{\circ} \mathrm{C}$. After $1 \mathrm{hr}$, the reaction mixture was removed from the water bath, cooled and added $1 \mathrm{ml}$ of distilled water. $5 \mathrm{ml}$ of butanol: pyridine mixture $(15: 1)$ was added to the reaction tube and mixed well. After centrifugation at $3000 \mathrm{rpm}$ for $10 \mathrm{~min}$, the organic layer was withdrawn and absorbance was measured at $532 \mathrm{~nm}$ against blank. The content of Malondialdehyde (MDA) was expressed as nanomoles/mg protein.

\section{Preparation of serum}

At the end of the reperfusion (24 h), blood was collected from retroorbital plexus from the inner canthus of the eye (under light anesthesia) using glass capillary tubes. Serum was separated by centrifugation blood at $3000 \mathrm{rpm}$ for $15 \mathrm{~min}$. The serum was used for estimation of lactate dehydrogenase (LDH) and serum nitrite concentration.

\section{Estimation of lactate dehydrogenase (LDH)}

The quantitative determination of the activity of lactate dehydrogenase (LDH) in serum was done using the enzymatic kit (LDH kit-Aspen Laboratories Pvt. Ltd., Baddi, India.).

\section{Estimation of serum nitrite}

It was estimated by according to the method of sastry et al. [30]. 400 $\mu \mathrm{l}$ of carbonate buffer ( $\mathrm{pH} 9.0$ ) was added to $100 \mu \mathrm{l}$ of serum or standards sample followed by addition of small amount of copper cadmium alloy. The tubes were incubated at room temperature for 1 $\mathrm{hr}$ to reduce nitrate to nitrite. The reaction was stopped by adding $100 \mu \mathrm{l}$ of $0.35 \mathrm{M}$ sodium hydroxide $(\mathrm{NaOH})$, followed by $400 \mu \mathrm{l}$ of zinc sulfate $(120 \mathrm{nM})$ was added to deproteinate the serum samples. The samples was allowed to stand for $10 \mathrm{~min}$ and then centrifuged at $4000 \mathrm{rpm}$ for $10 \mathrm{~min}$. Aliquots $(500 \mu \mathrm{l})$ of the clear supernatant were transferred to another test tube and $250 \mu \mathrm{l} 1.0 \%$ sulfanilamide (prepared in $3 \mathrm{~N} \mathrm{HCl}$ ) and $250 \mu \mathrm{l} 0.1 \% \mathrm{~N}$-naphthylethylenediamine (prepared in water) was added with shaking. After $10 \mathrm{~min}$ the absorbance was measured at $545 \mathrm{~nm}$ against a blank containing the same concentration of ingredients but no biological sample. Serum nitrite concentration was calculated by using a standard curve of sodium nitrite.

\section{Statistical analysis}

All data were expressed as mean \pm standard error mean (SEM). All data were statically analysed using one-way analysis of variance (ANOVA) followed by Tukey's multiple range test for multiple comparison among various groups respectively.

\section{RESULTS}

Effect of zafirlukast on global cerebral ischemia/reperfusioninduced increase in thiobarbituric acid reactive substances (TBARS).

Global cerebral ischemia of 17 min followed by $24 \mathrm{~h}$ reperfusion produced a significant ( $\mathrm{p}=\leq 0.001$ ) increase the TBARS level in I/R injury group as compared to the control and sham group. There was no significant difference observed between control and sham control group when TBARS level was compared. Administration of high dose 
of zafirlukast (20 mg/kg, p. o.) decrease more significantly ( $\mathrm{p}=$ $\leq 0.01)$ TBARS level as compared to the low and medium dose of zafirlukast (5 and $10 \mathrm{mg} / \mathrm{kg}$, p. o.), zafirlukast ( $5 \mathrm{mg} / \mathrm{kg}$, p. o.) and nifedipine ( $5 \mathrm{mg} / \mathrm{kg}$, i. p.) in combination reduced more significantly $(p=\leq 0.001)$ TBARS level as compare to individual administration of zafirlukast (fig. 1).

Effect of zafirlukast on global cerebral ischemia/reperfusioninduced on serum lactate dehydrogenase (LDH)

Global cerebral ischemia of $17 \mathrm{~min}$ followed by $24 \mathrm{~h}$ reperfusion produced a significant $(\mathrm{p}=\leq 0.001)$ increase in LDH level in I/R injury group compared to the control and sham group. There was no significant difference observed between control and sham control group when LDH level was compared. Administration of high dose of zafirlukast (20 mg/kg, p. o.) decrease more significantly ( $\mathrm{p}=\leq 0.001$ ) LDH level in blood serum as compare to the low and medium dose of zafirlukast (5 and $10 \mathrm{mg} / \mathrm{kg}$, p. o.), zafirlukast ( $5 \mathrm{mg} / \mathrm{kg}$, p. o.) and nifedipine ( $5 \mathrm{mg} / \mathrm{kg}$, i. p.) in combination reduced more significantly ( $\mathrm{p}=\leq 0.001)$ LDH level in blood as compare to individual administration of zafirlukast (fig. 2).

Effect of zafirlukast on global cerebral ischemia/reperfusioninduced on serum nitrite level

Global cerebral ischemia of $17 \mathrm{~min}$ followed by $24 \mathrm{~h}$ reperfusion produced a significant $(\mathrm{p}=\leq 0.001)$ increase in level serum total nitrate/nitrite level in I/R injury group compared to the control and sham control group. There was no significant difference observed between control and sham control group when serum nitrite level was compared. Administration of high dose of zafirlukast (20 mg/kg, p. o.) decrease more significantly $(p=\leq 0.001)$ serum nitrite level as compare to the low and medium dose of zafirlukast (5 and $10 \mathrm{mg} / \mathrm{kg}$ p. o.), zafirlukast ( $5 \mathrm{mg} / \mathrm{kg}$, p. o.) and nifedipine $(5 \mathrm{mg} / \mathrm{kg}$, i. p.) in combination reduced more significantly $(p=\leq 0.001)$ serum nitrite level as compared to individual administration of zafirlukast (fig. 3).

Effect of zafirlukast on global cerebral ischemia/reperfusioninduced cerebral infarct size

Global cerebral ischemia of $17 \mathrm{~min}$ followed by $24 \mathrm{~h}$ reperfusion produced significant ( $\mathrm{p}=\leq 0.001$ ) increase the cerebral infarct size in the negative control group compared to the control and sham group when measured by both volume and weight method. There was no significant difference observed between control and sham control group when cerebral infarct size measured by both volume and weight methods. Administration of high dose of zafirlukast (20 $\mathrm{mg} / \mathrm{kg}$, p. o.) decrease more significantly $(\mathrm{p}=\leq 0.001$ and $\mathrm{p}=\leq 0.01)$ cerebral infarct size as compare to low and medium dose of zafirlukast ( 5 and $10 \mathrm{mg} / \mathrm{kg}$, p. o.), zafirlukast ( $5 \mathrm{mg} / \mathrm{kg}, \mathrm{p}$. o.) and nifedipine $(5 \mathrm{mg} / \mathrm{kg}$, i. p.) in combination reduced more significantly $(\mathrm{p}=\leq 0.001)$ cerebral infarct size as compare to individual administration of zafirlukast (fig. 4, 5 and 6).

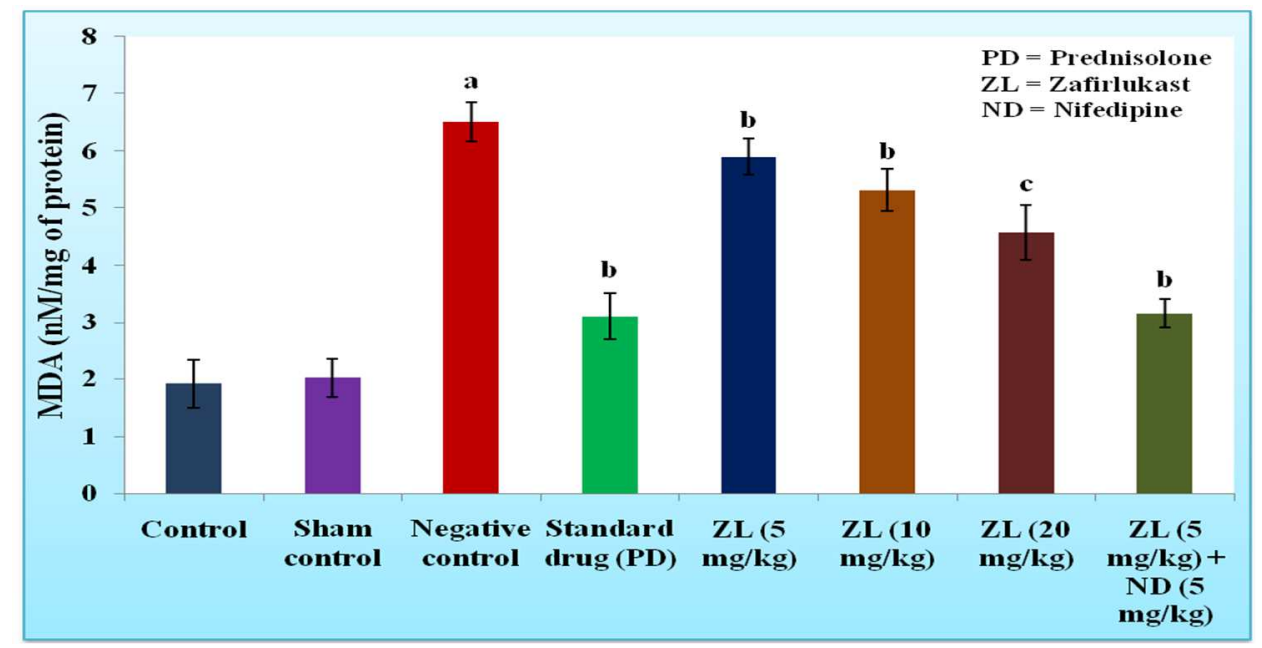

Fig. 1: Effect of zafirlukast on global cerebral ischemia and reperfusion injury induced on thiobarbituric acid reactive substances (TBARS) level. All data are expressed as mean $\pm S E M, n=6, a=p \leq 0.001$ Vs control group; $b=p \leq 0.001$ Vs negative; $c=p \leq 0.01$ Vs negative control group

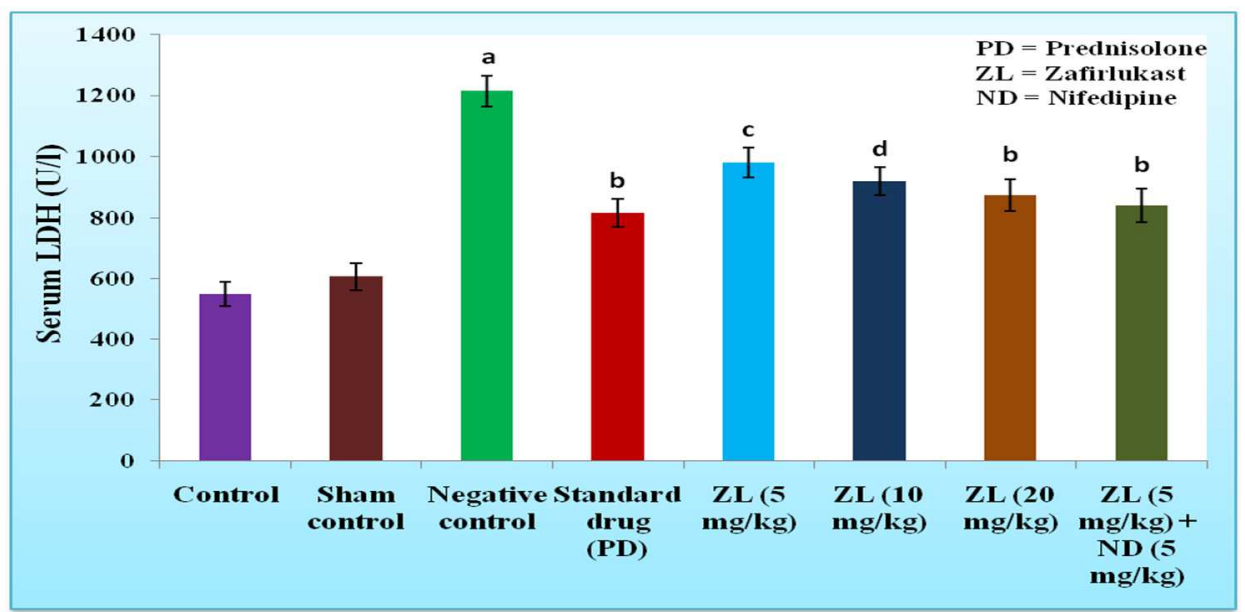

Fig. 2: Effect of zafirlukast on global cerebral ischemia/reperfusion injury induced on lactate dehydrogenase (LDH). All data are expressed as mean $\pm S E M, n=6, a=p \leq 0.001$ Vs control group; $b=p \leq 0.001$ Vs negative; $c=p \leq 0.01$ Vs negative control; $d=p \leq 0.05$ Vs negative control group 


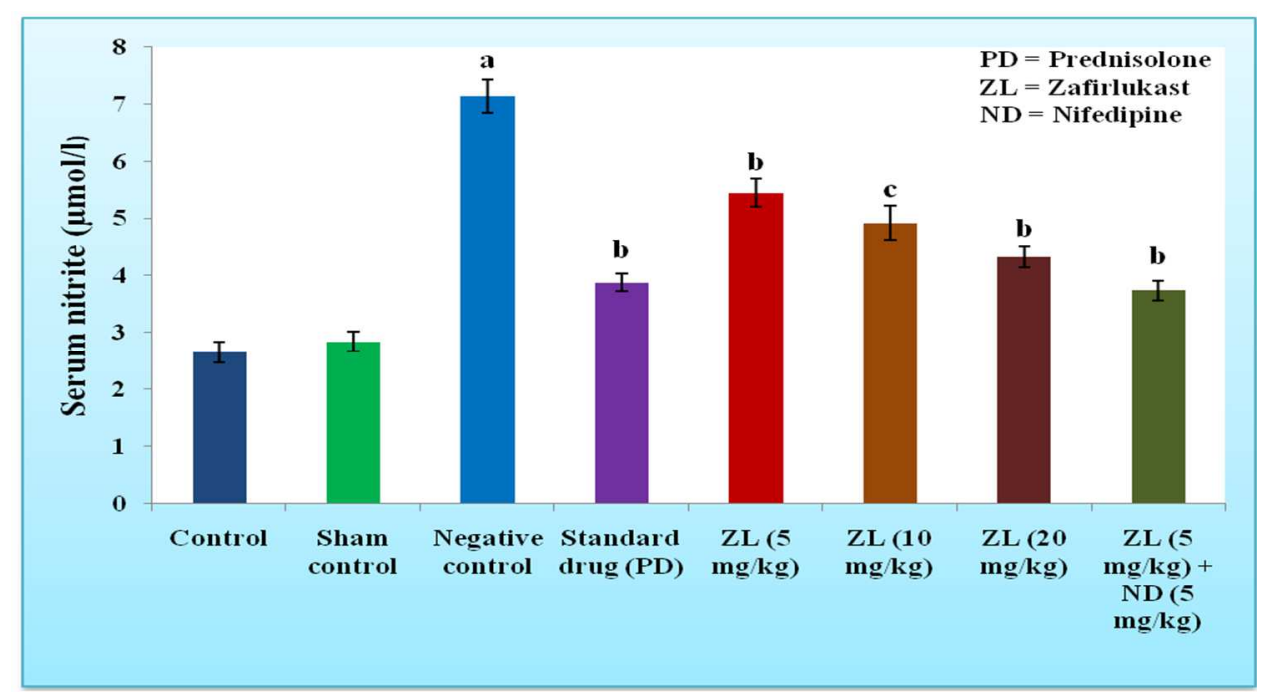

Fig. 3: Effect of zafirlukast on global cerebral ischemia and reperfusion injury induced on serum nitrite level. All data are expressed as mean $\pm S E M, n=6, a=p \leq 0.001$ Vs control group; $b=p \leq 0.001$ Vs negative; $c=p \leq 0.01$ Vs negative control group

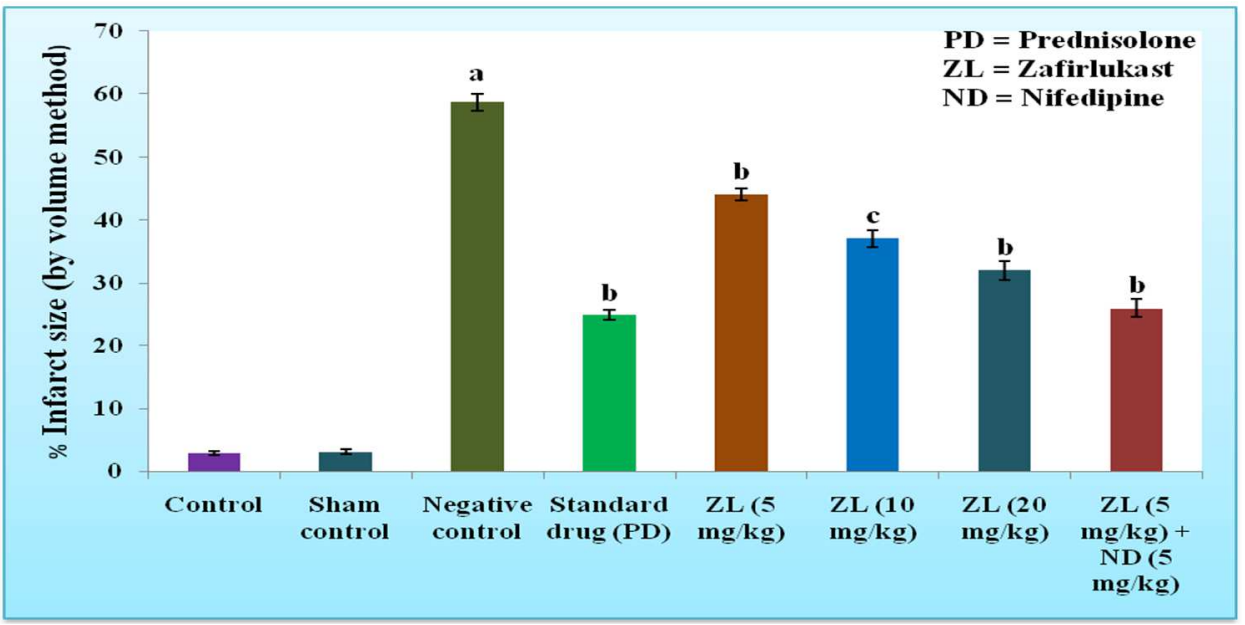

Fig. 4: Effect of zafirlukast on global cerebral ischemia/reperfusion injury induced cerebral infarct size in mice by volume method. All data are expressed as mean $\pm S E M, n=6, a=p \leq 0.001$ Vs control group; $b=p \leq 0.001$ Vs negative; $c=p \leq 0.01$ Vs negative control group

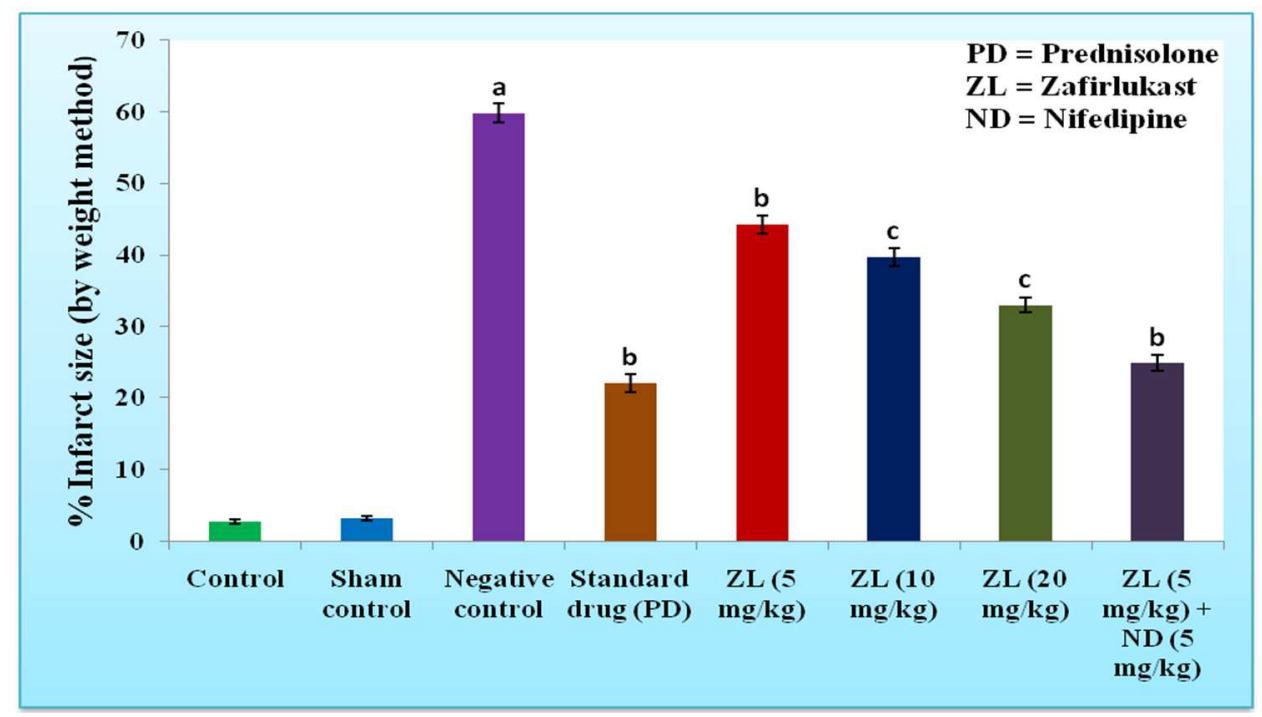

Fig. 5: Effect of Zafirlukast on global cerebral ischemia/reperfusion injury induced cerebral infarct size in mice by a weight method. All data are expressed as mean $\pm S E M, n=6, a=p \leq 0.001$ Vs control group; $b=p \leq 0.001$ Vs negative; $c=p \leq 0.01$ Vs negative control group 


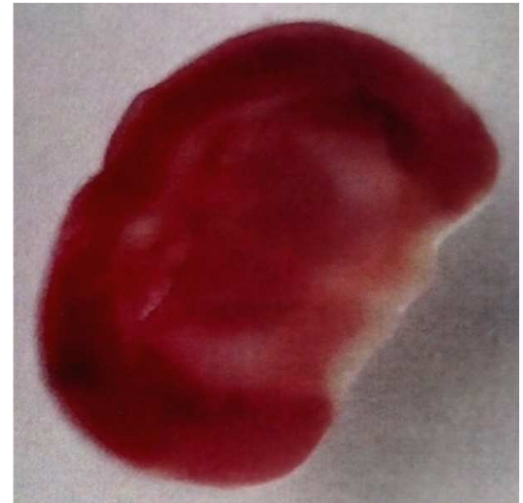

A

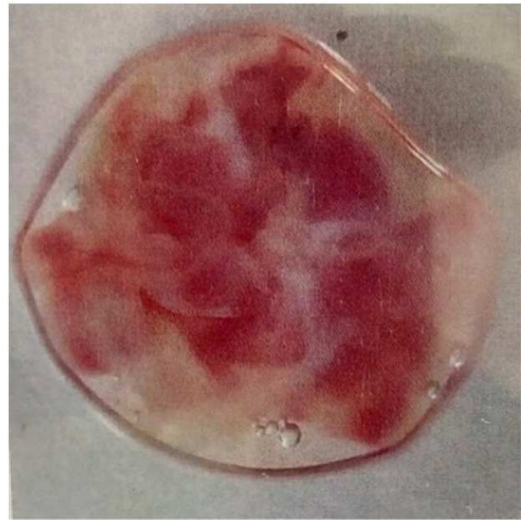

C

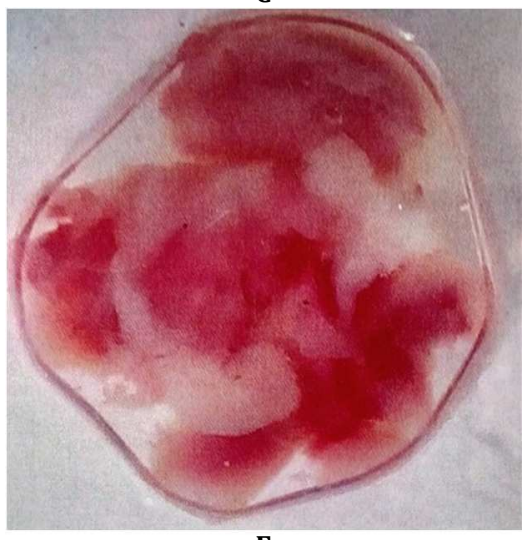

E

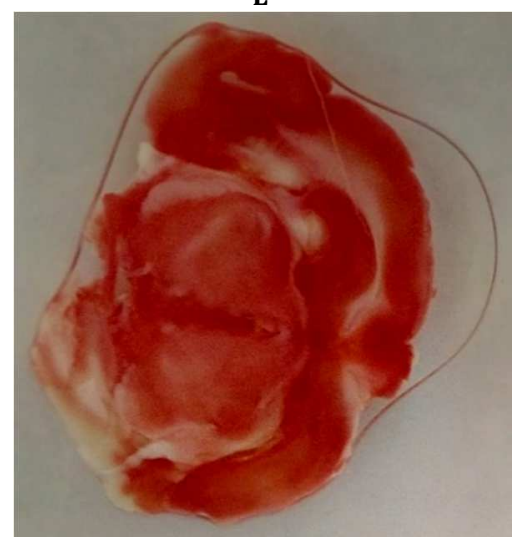

G

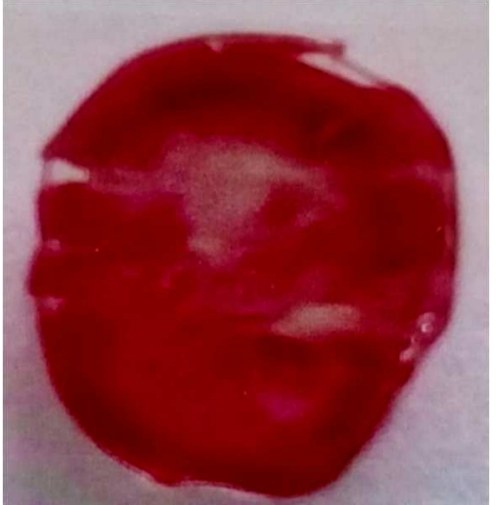

B

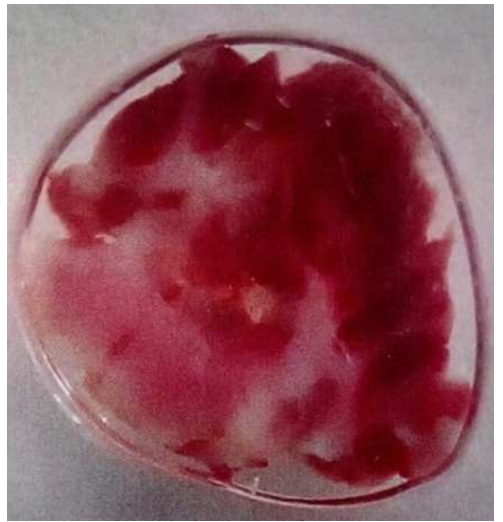

D

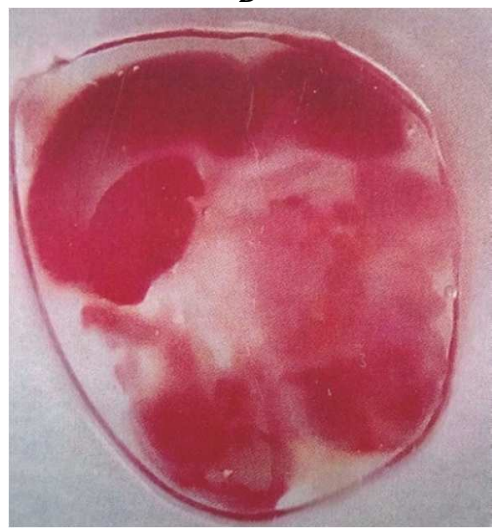

F

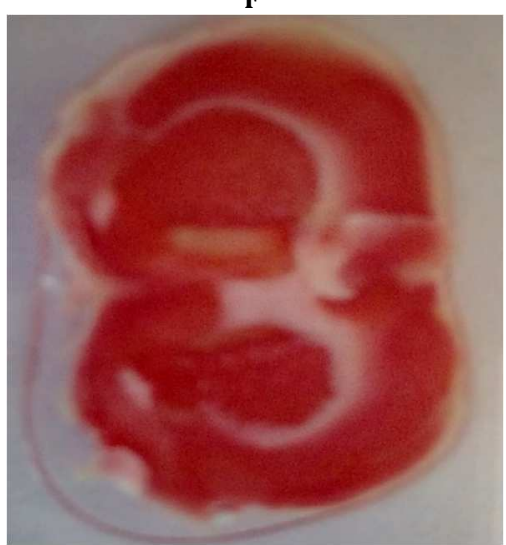

H

Fig. 6: Effect of zafirlukast against global cerebral ischemia/reperfusion injury in mice evaluated by 2,3,5-triphenyltetrazolium chloride (TTC) staining. Brain coronal sections were prepared and each section was stained with TTC. (A) Control: normal animal, (B) Sham control: Carotid arteries were exposed for 17 min, (C) Negative control: distilled water+ischemia for 17 min, (D) Standard: Prednisolone $(5 \mathrm{mg} / \mathrm{kg}$, p. o.)+ischemia for $17 \mathrm{~min}$, (E) Zafirlukast (5 mg/kg, p. o.)+ischemia for $17 \mathrm{~min})$, (F) Zafirlukast (10 mg/kg, p. o.)+ischemia for $17 \mathrm{~min}$, (G) Zafirlukast (20 mg/kg, p. o.)+ischemia for $17 \mathrm{~min}$, (H) Zafirlukast+Nifedipine (5 mg/kg, p. o.+5 mg/kg, i. p.)+ischemia for 17 min. The infarction was markedly reduced in the mice brain with $(\mathrm{H})$ 


\section{DISCUSSION}

In the present study was designed to investigate the role of zafirlukast in experimentally induced global cerebral ischemia/reperfusion $(I / R)$ injury in mice. It is well known that stroke is a sudden loss of brain function due to alteration in cerebral circulation with symptoms lasting at least for $24 \mathrm{~h}$ and this may lead to death. Stroke is neurological dysfunction and it can occur both global and focal impairments including hemiparesis, asthenia, severe headache and blackouts [32]. Basically, stroke caused by either thrombosis (ischemic stroke) or rupture of a blood vessel (hemorrhagic stroke) [33]. The exact mechanism involved in ischemic stroke through pathophysiological processes such as oxidative stress, activation of voltage-gated calcium channel, inflammation, excitotoxicity, apoptosis and necrosis. After ischemia, oxidative stress and inflammation plays a very important role in brain damage [8]. Various studies have established that neuronal injuries are developing when cerebral ischemia occurs. The bilateral carotid artery (BCA) occlusion for 10-20 min is the most easy and common form to induce ischemia. Therefore, in the study global cerebral ischemia was induced by occluding common carotid arteries for 17 min followed by reperfusion for $24 \mathrm{~h}$ [27]. It was indicated by the elevation of lipid peroxidation, lactate dehydrogenase level, serum nitrite concentration and cerebral infarct size in our study.

Oxidative stress plays important role in damage of the brain. In ischemic condition, level of oxygen are depleted in brain cells since glucose are favoring to the pathway of anaerobic ATP production. This result in $\mathrm{H}^{+}$and lactic acid production within the mitochondria and the subsequent reversal $\mathrm{H}^{+}$uniporter on the mitochondrial membrane which act as highly $\mathrm{H}^{+}$aggregation and acidosis [35]. Enormous formation of reactive oxygen species (ROS) at the time of ischemia/reperfusion lead to the damage of proteins, lipids and nucleic acid, thereby lead to apoptosis or necrosis [36]. In this study, leukocyte play a vital role in mediating inflammatory response on ischemia. After ischemia, leukocyte and microglia are activated and aggregation within tissue of brain and leading to the inflammatory response. Also, astrocytes show the inflammatory response at ischemic stroke [25]. When there is an imbalance between oxidants and antioxidants or means by increasing free radicals, as a result, enhance the activity of 5-lipooxygenase (5-LO) and leukotrienes (LTs) in the ischemic area [37]. The content of arachidonic acid (AA) level was higher in brain region should be confirmed and leukotrienes (LTs), as well as 5-lipooxygenase (5-LO), were elevated in ischemic region, it demonstrates LTs play important role in cerebral ischemia. Because leukotrienes are inflammatory mediators which contain polymorphonuclear leukocytes (PMN) and it is the first line defense to reach the ischemic area [15].

Reactive oxygen species (ROS) produces malondialdehyde (MDA), which is end product of lipid peroxidation. The concentration of MDA was assayed as an index of membrane oxidative damage [38]. In the present study, MDA was evaluated using TBARS assay to estimate extent of reactive oxygen species formation [39]. Global cerebral ischemia/reperfusion-induced in mice showed the statistical significant increase oxidative stress levels as, determined by increased TBARS levels, as a compared control group. Administration of high dose of zafirlukast $(20 \mathrm{mg} / \mathrm{kg}$, p. o.) decrease more significantly TBARS level as compared to the low and medium dose of zafirlukast ( 5 and 10 $\mathrm{mg} / \mathrm{kg}$, p. o.), zafirlukast ( $5 \mathrm{mg} / \mathrm{kg}$, p. o.) and nifedipine ( $5 \mathrm{mg} / \mathrm{kg}$, i. p.) in combination reduced more significantly TBARS level as compare to individual administration of zafirlukast.

Lactate dehydrogenase (LDH) serves as a very important metabolic enzyme in neuron form injured neuron to blood and it is released into the bloodstream from damage cerebral cells [40]. Thus, level of LDH in serum is a reliable index to investigate ischemic injury. The pretreatment treatment with high dose of zafirlukast $(20 \mathrm{mg} / \mathrm{kg}$, p. o.) decrease more significantly LDH level as compared to the low and medium dose of zafirlukast ( 5 and $10 \mathrm{mg} / \mathrm{kg}, \mathrm{p} . \mathrm{o}$.), zafirlukast $(5 \mathrm{mg} / \mathrm{kg}$, p. o.) and nifedipine $(5 \mathrm{mg} / \mathrm{kg}$, i. p.) in combination reduced more significantly LDH level as compared to individual administration of zafirlukast.

Nitric oxide (NO) is a transient gaseous second messenger molecule functioning in immunity, neurotransmission and vascular regulation.
The level of NO directly linked with the development of brain damage in strokes and other neuropathological disorders in humans [42]. The pretreatment with high dose of zafirlukast $(20 \mathrm{mg} / \mathrm{kg}$, $\mathrm{p}$. o.) decrease more significantly serum nitrite level as compared to the low and medium dose of zafirlukast ( 5 and $10 \mathrm{mg} / \mathrm{kg}, \mathrm{p.} \mathrm{o.)}$, zafirlukast $(5 \mathrm{mg} / \mathrm{kg}$, p. o.) and nifedipine $(5 \mathrm{mg} / \mathrm{kg}$, i. p.) in combination reduced more significantly serum nitrite level as compared to individual administration of zafirlukast.

The zafirlukast exhibited neuroprotection as is evident from the reduction of infarct size. Global cerebral ischemia was induced by bilateral carotid artery occlusion (BCA0) for 17 min followed by reperfusion for $24 \mathrm{~h}$. It is well known that global cerebral ischemia causes neurological dysfunction. Triphenyltetrazolium chloride (TTC) staining was employed in the current study to determine the infarction area of the brain. Triphenyltetrazolium chloride (TTC) was water-soluble dye that is reduced to the formation of red formazone by the succinate dehydrogenase enzyme and nicotinamide adenine dinucleotide (NAD) cofactor. The stain viable tissue occurs in red color and damaged mitochondria with ischemic tissue remain unstained [27]. Administration of high dose of zafirlukast $(20 \mathrm{mg} / \mathrm{kg}$, p. o.) decrease more significantly cerebral infarct size as compare to low and medium dose of zafirlukast ( 5 and $10 \mathrm{mg} / \mathrm{kg}$, p. o.), zafirlukast (5 mg/kg, p. o.) and nifedipine (5 mg/kg, i. p.) in combination reduced more significantly cerebral infarct size as compare to individual administration of zafirlukast.

The results indicate that cysteinyl leukotrienes antagonist zafirlukast was good neuroprotective effect and could be used as a therapeutic treatment in ischemic stroke.

\section{CONCLUSION}

Our findings clearly demonstrate cysteinyl leukotrienes antagonist with zafirlukast introduce a strong anti-inflammatory and antioxidant effect. Our results constitute the new evidence for the neuroprotective of leukotrienes antagonists and it need for further clinical and experimental studies that will explain the clinical opportunity of therapy with zafirlukast as an exclusive agent for patient suffering from a stroke.

\section{ACKNOWLEDGEMENT}

The authors are thankful to Shri Mahant Devendra Dass Ji Maharaj, Chairman, Shri Guru Ram Rai Education Mission, Dehradun, Uttarakhand, for providing necessary instruments and financial support.

\section{AUTHORS CONTRIBUTIONS}

Bipin Kumar Nayak performed the experimental work and assessed the data.

Arun Kumar guided the research work.

Preeti Kothiyal is a director of our institution and supports the research work.

\section{CONFLICT OF INTERESTS}

We declare that we have no conflict of interest

\section{REFERENCES}

1. Roger VL, Go AS, Lloyd-Jones DM, Benjamin EJ, Berry JD, Borden WB, et al. Heart disease and stroke statistics--2012 update: a report from the american heart association. Circulation 2012;125:2-220.

2. Chang Y, Hung S, Ling W, Lin H, Li H, Chung S. Association between ischemic stroke and iron-deficiency anemia: a population-based study. PLoS One 2013;8:82952.

3. Hankey G. Anticoagulant therapy for patients with ischemic stroke. Nat Rev Neurol 2012;8:319-28.

4. Penton-Rol G, Marin-Prida J, Pardo-Andreu G, MartinezSanchez G, Acosta-Medina E, Valdivia-Acosta A, et al. CPhycocyanin is neuroprotective against global cerebral ischemia/reperfusion injury in gerbils. Brain Res Bull 2011;86:42-52.

5. Donnan G, Fisher M, Macleod M, Davis S. Stroke. J Lancet 2008;371:1612-23. 
6. Ringelstein E, Nabavi D. Cerebral small vessel diseases: cerebral microangiopathies. Curr Opin Neurol 2005;18:179-88.

7. Lim C, Alexander M, La Fleche G, Schnyer D, Verfaellie M. The neurological and cognitive sequelae of cardiac arrest. Neurology 2004;63:1774-8.

8. El-Sahar A, Safar M, Zaki H, Attia A, Ain-Shoka A. Neuroprotective effects of pioglitazone against transient cerebral ischemic reperfusion injury in diabetic rats: modulation of antioxidant, anti-inflammatory, and antiapoptotic biomarkers. Pharmacol Rep 2015;67:901-6.

9. Gao Y, Xu X, Chang S, Wang Y, Xu Y, Ran S, et al. Totarol prevents neuronal injury in vitro and ameliorates brain ischemic stroke: potential roles of Akt activation and HO-1 induction. Toxicol Appl Pharmacol 2015;289:142-54.

10. Shu Y, Yang Y, Zhang P. Neuroprotective effects of penehyclidine hydrochloride against cerebral ischemia/ reperfusion injury in mice. Brain Res Bull 2016;121:115-23.

11. Pujari R, Vyawahare N, Thakurdesai P. Protective effects of Phoenix dactylifera against oxidative stress and neuronal damage induced by global cerebral ischemia in rats. Biomed Aging Pathol 2013;3:75-81.

12. Yang Y, Jiang S, Dong Y, Fan C, Zhao L, Yang X, et al. Melatonin prevents cell death and mitochondrial dysfunction via a SIRT1dependent mechanism during ischemic-stroke in mice. J Pineal Res 2014;58:61-70.

13. Daou B, Deprince M, D'Ambrosio R, Tjoumakaris S, Rosenwasser $\mathrm{R}$, Ackerman $\mathrm{D}$, et al. Pennsylvania comprehensive stroke center collaborative: Statement on the recently updated IV rt-PA prescriber information for acute ischemic stroke. Clin Neurol Neurosurg 2015;139:264-8.

14. Kang S, Shin K, Kim W, Bae T, Kim H, Kim M. The preventive effect of topical zafirlukast instillation for peri-implant capsule formation in rabbits. Arch Plast Surg 2015;42:179-85.

15. O'Byrne PM, Israel E, Drazen JM. Antileukotrienes in the treatment of asthma. Ann Intern Med 1997;127:472-80.

16. Salmon JA, Higgs GA. Prostaglandins and leukotrienes as inflammatory mediators. Br Med Bull 1987;43:285-96.

17. Samitas K, Chorianopoulos D, Vittorakis S, Zervas E, Economidou E, Papatheodorou G, et al. Exhaled cysteinylleukotrienes and 8-isoprostane in patients with asthma and their relation to clinical severity. Respir Med 2009;103:750-6.

18. Kumar S, Verma AK, Das M, Dwivedi PD. Molecular mechanisms of IgE mediated food allergy. Int Immunopharmacol 2012;13:432-9.

19. Kitano K, Usui S, Ootsuji H, Takashima S, Kobayashi D, Murai H, et al. Rhokinase activation in leukocytes plays a pivotal role in myocardial ischemia/reperfusion injury. PLoS One 2014; 9:92242.

20. Zhao H, Perez JS, Lu K, George AJ, Ma D. Role of toll-like receptor 4 in renal graft ischemia-reperfusion injury. Am J Physiol Renal Physiol 2014;306:801-11.

21. Grisham MB, Hernandez LA, Granger DN. Xanthine oxidase and neutrophil infiltration in intestinal ischemia. Am J Physiol 1986;251:567-74.

22. Parks DA, Bulkley GB, Granger DN, Hamilton SR, McCord JM. Ischemic injury in the cat small intestine: role of superoxide radicals. Gastroenterology 1982;82:9-15.

23. Corser-Jensen C, Goodell D, Freund R, Serbedzija P, Murphy R, Farias S, et al. Blocking leukotriene synthesis attenuates the pathophysiology of traumatic brain injury and associated cognitive deficits. Exp Neurol 2014;256:7-16.

24. Shi SS, Yang WZ, Tu XK, Wang $\mathrm{CH}$, Chen CM, Chen Y. 5Lipoxygenase inhibitor zileuton inhibits neuronal apoptosis following focal cerebral ischemia. Inflammation 2013;36:1209-17.
25. Saad MA, Abdelsalam RM, Kenawy SA, Attia AS. Montelukast, a cysteinyl leukotriene receptor-1 antagonist protects against hippocampal injury induced by transient global cerebral ischemia and reperfusion in rats. Neurochem Res 2015;40:139-50.

26. Himori N, Watanabe $\mathrm{H}$, Akaike N, Kurasawa M, Itoh J, Tanaka Y. Cerebral ischemia model with conscious mice. Involvement of NMDA receptor activation and derangement of learning and memory ability. J Pharmacol Methods 1990;23:311-27.

27. Rehni AK, Bhateja P, Singh N. Diethyl dithicarbamic acid, a possible nuclear factor kappa B inhibitor, attenuates ischemic postconditioning-induced attenuation of cerebral ischemiareperfusion injury in mice. Can J Physiol Pharmacol 2009;87:63-8.

28. Sharma V, Subrahmanya GS, Kumar AG. The effect of minocycline on oxidative stress and memory deficits in aged rats. Int J Pharm 2012;2:71-9.

29. Lowry $\mathrm{OH}$, Rosebrough NJ, Farr AL, Randall RJ. Protein measurement with folin phenol reagent. J Biol Chem 1951;193:265-75.

30. Ohkawa H, Ohishi N, Yagi K. Assay for lipid peroxides in animal tissues by the thiobarbituric acid reaction. Anal Biochem 1979;95:351-8.

31. Sastry KV, Moudgal RP, Mohan J, Tyagi JS, Rao GS. Spectrophotometric determination of serum nitrite and nitrate by copper-cadmium alloy. Anal Biochem 2002;306:79-82.

32. Hinkle JL, Guanci MM. Acute ischemic stroke review. J Neurosci Nurs 2007;39:285-310.

33. Woodruff TM, Thundyil J, Sung Chung T, Sobey CG, Taylor SM, Arumugam TV. Pathophysiology, treatment and animal and cellular models of human ischemic stroke. Mol Neurodegener 2011;6:2-19.

34. Kumar PAB, Panchal S. Neuroprotective effect of cromakalim on cerebral ischemia-reperfusion (IR) injury and aluminium induced toxicity in rat brain. Int $\mathrm{J}$ Pharm Pharm Sci 2014;6:392-6.

35. Phachonpai W, Maharun S, Tong-Un T, Muchimapura S, Wattanathorn J. The functional effect of kaempferia parviflora on ischemic stroke in rats. Am J Agric Biol Sci 2012;7:173-9.

36. Brouns R, De Deyn PP. The complexity of neurobiological processes in acute ischemic stroke. Clin Neurol Neurosurg 2009;111:483-95.

37. Rodrigues SF, Granger DN. Leukocyte-mediated tissue injury in ischemic stroke. Curr Med Chem 2014;21:2130-7.

38. Globus MY, Alonso O, Dietrich WD, Busto R, Ginsberg MD. Glutamate release and free radical production following brain injury: effects of posttraumatic hypothermia. J Neurochem 1995;65:1704-11.

39. Dib M, Garrel C, Favier A, Robin V, Desnuelle C. Can malondialdehyde be used as a biological marker of progression in neurodegenerative disease? J Neurol 2002;249:367-74.

40. Guo Y, Chen ZW. Protective effects of total flavones of rhododendra on cerebral ischemia-reperfusion injury. Am J Chin Med 2008;36:343-54.

41. Naka M, Nanbu T, Kobayashi K, Kamanaka Y, Komeno M, Yanase $\mathrm{R}$, et al. A potent inhibitor of inducible nitric oxide synthase, ONO-1714, a cyclic amidine derivative. Biochem Biophys Res Commun 2000;270:663-7.

42. Veltkamp R, Rajapakse N, Robins G, Puskar M, Shimizu K, Busija D. Transient focal ischemia increases endothelial nitric oxide synthase in cerebral blood vessels. Stroke 2002;33:2704-10.

43. Bederson JB, Pitts LH, Tsuji M, Nishimura MC, Davis RL, Bartkowski H. Rat middle cerebral artery occlusion: evaluation of the model and development of a neurologic examination. Stroke 1986;17:472-6. 